\title{
A new kind of resin-based wet friction material: Non-woven fabrics with isotropic fiber networks as preforms
}

\author{
Yewei FU*, Le ZHOU, Tao YIN, Zhongyao LUO, Hejin LI, Lehua QI \\ Northwestern Polytechnical University, Xi'an 710072, China \\ Received: 21 August 2019 / Revised: 26 August 2019 / Accepted: 03 September 2019 \\ (C) The author(s) 2019.
}

State Key Laboratory of Solidification Processing, Shaanxi Province Key Laboratory of Fiber Reinforced Light Composite Materials,

\begin{abstract}
As an alternative to short fibers, non-woven fabrics (NWFs) were made using different types of long fibers to optimize the performance of paper-based friction materials and their technology. In this investigation, the fillers and resin were impregnated into these NWFs to prepare three kinds of wet friction material. The tribological, mechanical, and thermal properties of the new wet friction material were studied. The results indicate that the dynamic friction coefficient of the new friction material is approximately 0.12 and the static friction coefficient is approximately 0.15 ; the better wear rate is $0.81334 \times 10^{-14} \mathrm{~m}^{3} \cdot(\mathrm{N} \cdot \mathrm{m})^{-1}$. In addition, the temperature for $10 \%$ mass loss yielded $100{ }^{\circ} \mathrm{C}$ enhancement and the tensile strength was improved by $200 \%$, compared to previously reported values. Most importantly, the advantages include a simple preparation flow, low cost, and resource conservation. This is a promising approach for the future development of paper-based friction materials.
\end{abstract}

Keywords: non-woven fabric; wet friction material; continued friction film; green manufacture speed

\section{Introduction}

Friction materials are widely used in automatic transmissions and clutches in automobiles [1-3]. Fiberreinforced resin-based friction material (FRRBFM) is an important category of friction material that is usually composed of fibers, adhesives, friction modifiers, and fillers [4-6]. As a kind of reinforcement, fibers impart physical strength to friction materials and provide thermal shock resistance. Cai et al. [7] studied the effect of the aspect ratios of aramid fiber on the mechanical and tribological performances of friction material. Li et al. [8] proposed the idea of a carbon fiber reinforced resin-based friction material.

Paper-based friction material is an important class of wet friction material, which is a kind of oil-immersed, polyporous FRRBFM. To improve the performance of a paper-based friction material, many researchers have undertaken theoretical studies on the composition of raw materials [1-6]. Recently, Zhou et al. [1] studied the effect of the synergistic effect of liquid carboxylated nitrile rubber and epoxy resin on a soft paper-based friction material. Fei et al. [2] electrodeposited silicon carbide particles on a paper-based friction material to enhance its performance. However, the current approaches for the preparation of paper-based friction materials are still based on the papermaking process. As such, the preforms have low strength and a large amount of water is consumed in the production process.

The application prospects of non-woven fabrics (NWFs) are promising, and they are generally used as masks and cushions in other textile products. NWFs are fabric-like material made of relatively long fibers that is prepared by chemical, mechanical, heat treatment or in combination with solvent treatment $[9,10]$. In the process of NWF production, fibers are loosely distributed, overlapped, and stitched, forming a randomly distributed structural layer with a welldefined pore structure and a large porosity [11].

* Corresponding author: Yewei FU, E-mail: yeweifu@nwpu.edu.cn 
Long-length and crimp-dispersed reinforced fibers were used to fabricate NWFs using two-dimensional (2D) plying and three-dimensional (3D) needle punching. These NWFs are akin to a strong fiber skeleton for composites, which helps the fibers of the wet friction material to bond more tightly to other components. It is expected to improve the performance of wet friction material and to contribute to energy conservation and environmental protection because of the improved fabrication process.

In this work, aramid fibers mixed with nylon fibers, charcoal fibers, and low-melting-point fibers represent three different blended NWFs that are used to make wet friction materials. Correspondingly, the production process for this material was changed. In practice, the frequent changes in speed, high brake pressure, and high-friction heat, requires that wet friction materials should have good mechanical and thermal properties [12-21]. Therefore, the tribological, mechanical, and thermal properties of the new wet friction materials were comprehensively studied and a mechanism was also proposed to explain the observed behavior.

\section{Experimental procedure}

\subsection{Raw materials}

The fibers include aramid fibers (linear density is $1.5 \mathrm{D}$, length is $51 \mathrm{~mm}$; Shandong Yantai Taihe Co., Ltd., China), nylon fiber, bamboo charcoal fiber, and low- melting fiber (linear density of nylon fiber, bamboo charcoal fiber, and low-melting fiber is $1.5 \mathrm{D}$, length of them is $51 \mathrm{~mm}$; Guangzhou Yuechengan Fiber Products Co., Ltd., China). The fillers consisted of mineral powder, chromite powder, fluorite powder, calcium carbonate, alumina, carbon black, and zinc stearate (all at industrial grades, particle size of 150-350 mesh). The binder was a mixture of $20 \mathrm{wt} \%$ phenolic resin modified with cashew nutshell (Jinan Sheng quan Hepworth Chemical Co., Ltd., China) and diluted with alcohol.

\subsection{Sample preparation}

\subsubsection{Preparation of NWF as preform}

The details of the manufacturing of NWF are presented in Fig. 1(a). The mixed fibers were processed using an opening machine, a cotton machine, a carding machine, and a needle punching machine to obtain an NWF with a density of 26 thorns $/ \mathrm{cm}^{2}$ that resembled a loose "fiber skeleton" (Fig. 1(b)). The mass fraction of the aramid fiber and hybrid fiber (nylon, charcoal, and low-melting point fiber) were 90 and $10 \mathrm{wt} \%$, respectively.

\subsubsection{Preparation of new resin-based friction material (NWF-wet friction material)}

The fillers were stirred in water at a speed of 2,000 rpm in a high-speed pulper. This allowed the fillers to be fully dissolved in water and a thick liquid similar to
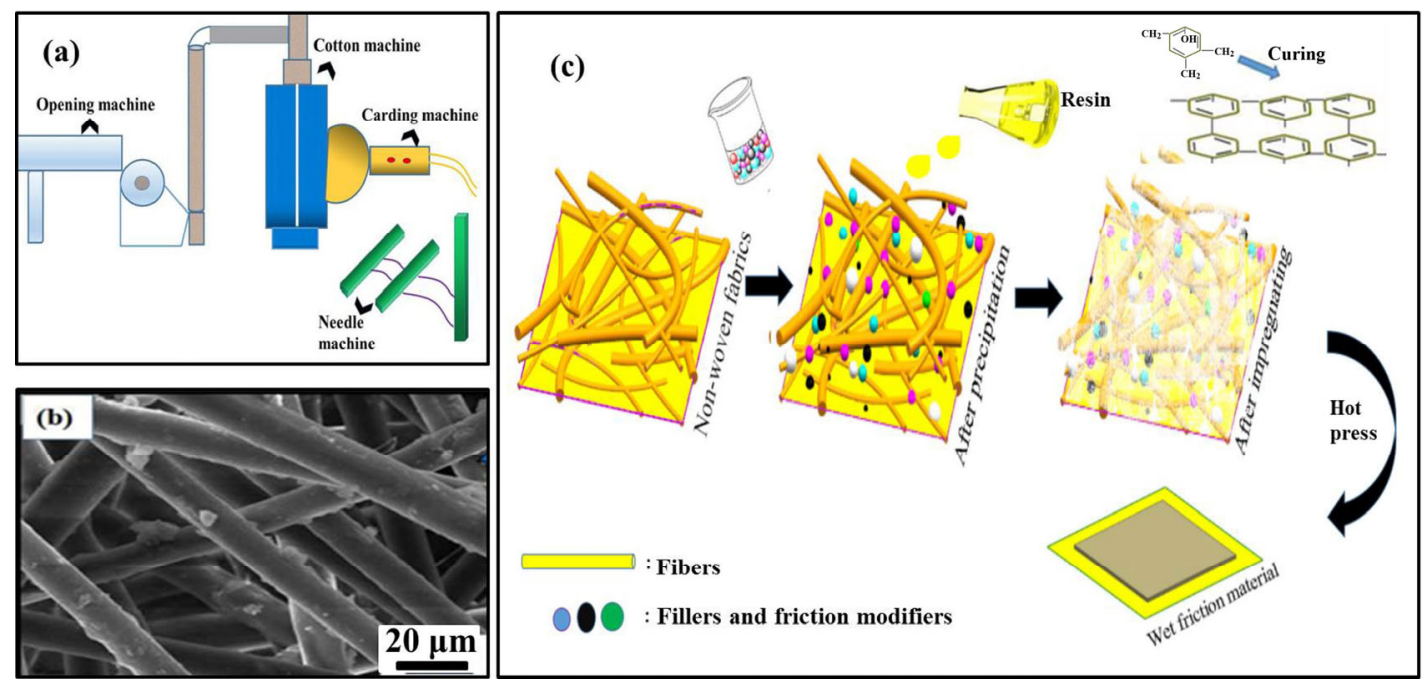

Fig. 1 (a) NWF manufacturing process, (b) the microstructure of NWF, and (c) schematic of overall fabrication process of the new kind of wet friction material. 
mud was obtained by suction filtration. The thick liquid was evenly spread over the surface of layers of fibers, and sufficient pressure was utilized to fully immerse the fibers. The fibers covered with the filler solution were dried at less than $100{ }^{\circ} \mathrm{C}$ for $1 \mathrm{~h}$. After drying, these preforms were impregnated with $20 \mathrm{wt} \%$ ethanol solution of phenolic resin until all the resin solutions were uniformly absorbed by the material substrate. This was followed by hot pressing on the vulcanizer at a temperature of $160{ }^{\circ} \mathrm{C}$ for approximately $5 \mathrm{~min}$ at a pressure of $5 \mathrm{MPa}$, to obtain wet friction materials with a thickness of $0.4 \mathrm{~mm}$. The mass fraction of the fibers, resin, and fillers was 30, 30, and $40 \mathrm{wt} \%$, respectively. Aramid fibers mixed with nylon fibers, charcoal fibers, and low-melting point fibers are separately designated as S1, S2, and S3, respectively. The schematic of the overall fabrication process is shown in Fig. 1(c).

\subsection{Testing method and equipment}

The unworn and worn surfaces of all samples were observed using scanning electron microscopy (SEM, JSM-6360, Japan). A wet friction performance tester (QM1000-IIB, Shuntong Co., Ltd., China) with a plateon-plate rotation mode was used to test the friction coefficient and wear rate of samples in lubricating oil (N32\#) at room temperature. (a) Sample size, (b) the location where the samples were tested, and (c) an image of the wet friction performance test machine are shown in Fig. 2. The material of the dual disk is $45 \#$ steel. The test mode was a single facing clutch test machine with a moment of inertia $0.1 \mathrm{~kg} \cdot \mathrm{m}^{2}$. The tribological tests were repeated three times for each sample. According to GB/T 1447-2005, the tensile strength of the materials was evaluated using a microcomputer-controlled electronic universal testing machine (CMT5304-30KN, Shenzhen Sansi universal testing machine, China). The mechanical tests were conducted five times for each sample. 3D contour topography images were acquired for the samples prior to wear measured a confocal microscope (LASERTEC OPTELICS C130). The porosity of the samples was measured using a mercury porosimeter (AutoPore IV 9500, American Mack Instruments). A thermal gravimetric analyzer (TGA/SDTA851,

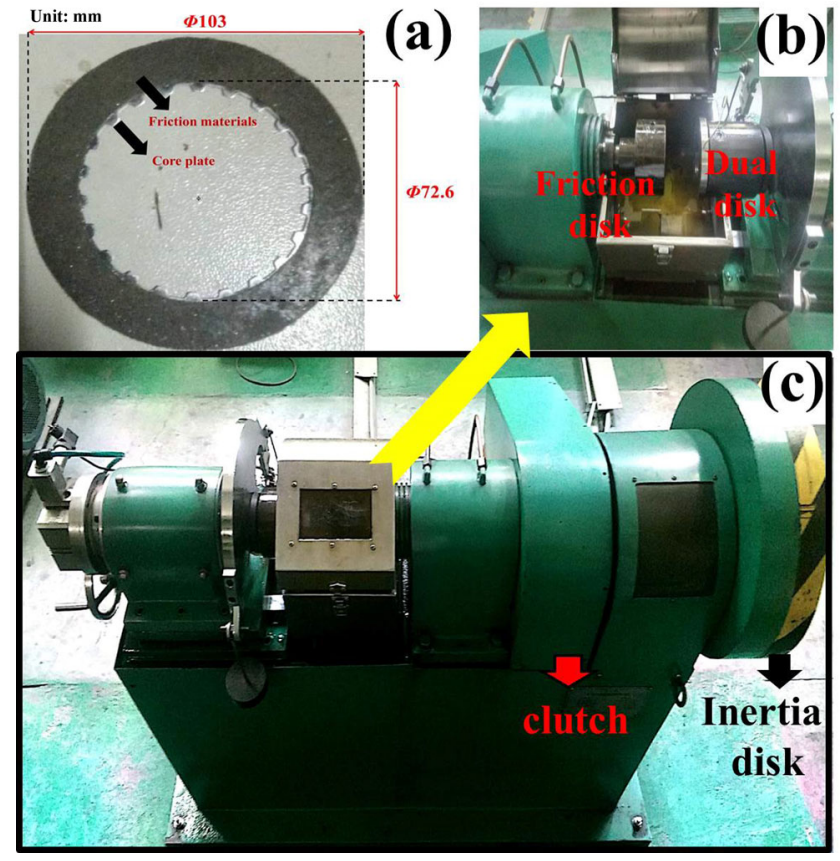

Fig. 2 (a) Sample size, (b) the location where the samples were tested, and (c) appearance of wet friction performance test machine.

METTLER TOLEDO) was utilized for TG-DTG analysis and the temperature range was from 40 to $800^{\circ} \mathrm{C}$ with a heating rate of $10{ }^{\circ} \mathrm{C} / \mathrm{min}$ and a flow rate of $50 \mathrm{ml} / \mathrm{min}$ under an air atmosphere.

\section{Results and discussion}

\subsection{Microstructure of the friction material}

Figure 1(b) shows the microstructure of the NWF. It is evident that the orientation of the fibers is intricate and cross-cutting, resulting in a large number of pores, which provides a rigid fiber skeleton as the preform for the new wet friction material.

It is evident from Figs. 3(a)-3(c) that the fillers and fibers of the three samples were bonded together using the resin. There are many interconnected holes on the surface of the new wet friction material. The presence of holes could allow the lubricant to penetrate the friction material, which is beneficial to the transfer and dissipation of heat in the friction process. The highmagnification SEM images (Figs. 3(g) and 3(h)) of the fibers in Fig. 3(a) indicate that the fiber clusters appear on the surface, and this unique surface topography is different from the fiber protrusion or exposure. Fibers 


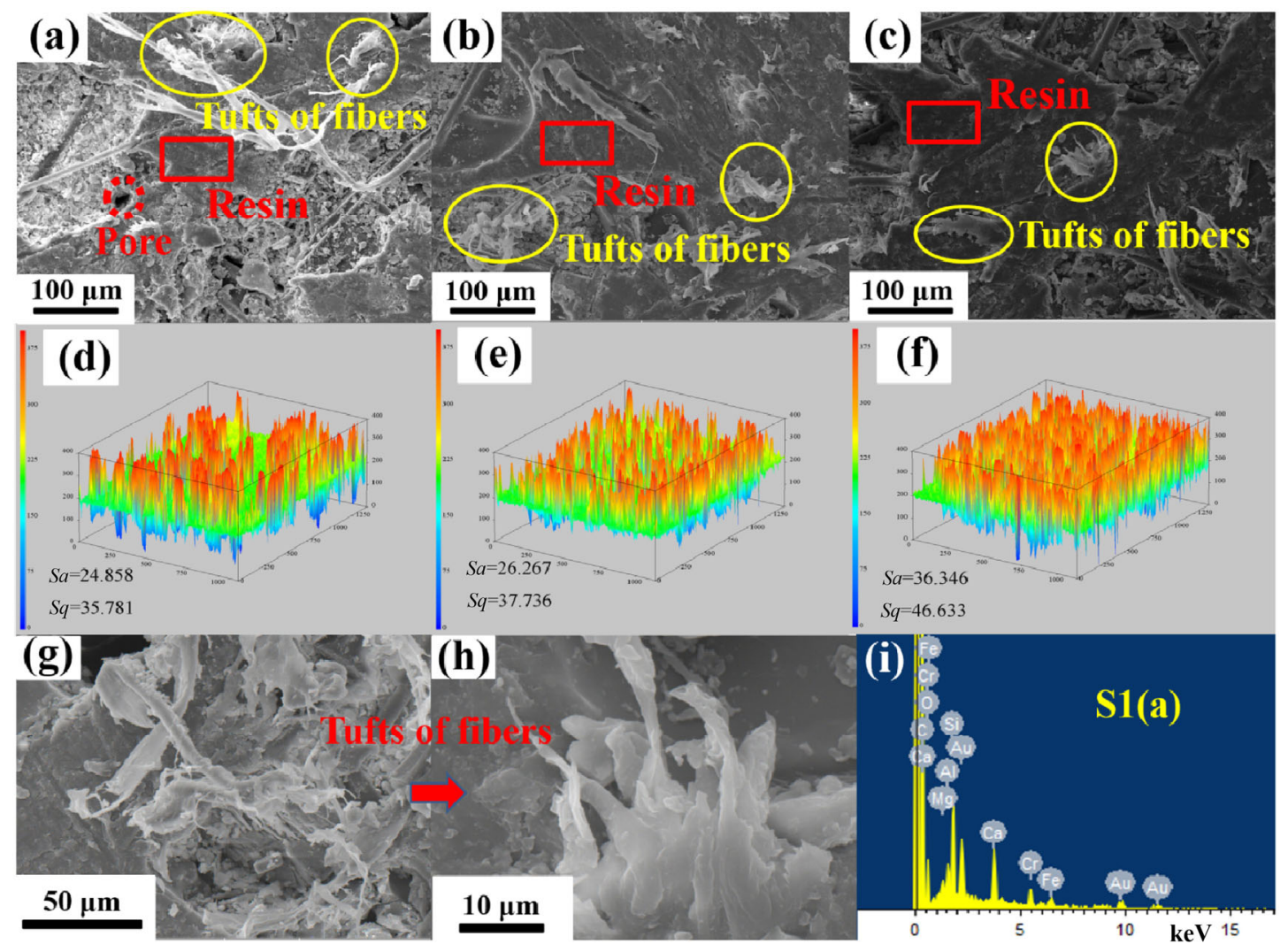

Fig. 3 SEM images of (a) S1, (b) S2, and (c) S3 before wear. Corresponding 3D surface profiles of different samples: (d) S1, (e) S2, and (f) S3. (g, h) High-magnification SEM images of fibers, and (i) energy disperse spectroscopy (EDS) spectroscopy for S1.

are peeled off to produce fine fibers due to fibrillation, which increases the specific surface area of the surface. EDS elemental analysis was performed on the local region of S1 (Fig. 3(a)). As shown in Fig. 3(i), it is evident that various elements such as $\mathrm{C}, \mathrm{O}, \mathrm{Ca}, \mathrm{Mg}$, $\mathrm{Fe}, \mathrm{Si}, \mathrm{Cr}$, and $\mathrm{Al}$ are distributed over the surface.

Figures 3(d)-3(f) show the 3D contour topography of these new materials. As a composite, the surface morphology of the wet friction material is anisotropic [22-24]. The $S q$ of the three samples are 35.781, 41.727, and $48.055 \mu \mathrm{m}$, respectively. Combined with the micromorphology analysis, it is determined that the surface structures of the three samples are similar and their roughness is not much different.

The porosity, as well as the size, and distribution of internal pores, have a great influence on the tribological properties, because they mainly control the formation of a lubricating film and a friction film during the wear process [26]. Figure 4 illustrates the porosity and pore diameter distribution of different new wet friction materials. From Fig. 4(a), the porosity values of S1, S2, and S3 are $38.67 \%, 41.94 \%$ and $43.45 \%$, respectively. The volume pore size distribution curves (Fig. 4(b)) show that the sizes of the pores are uniform, and mainly distributed in the range of $25-75 \mu \mathrm{m}$. This is indicative of the uniformity of these pores, which is beneficial to the stabilization of lubricating and friction films, and their continuous property.

\subsection{Mechanical performance}

To avoid affecting the performance and to prolong the service life of wet friction materials, they need to be able to withstand mechanical shock. Tensile strength tests were conducted to study the bonding strength between the reinforced fibers and resin. Figure 5 shows the tensile strength and load-displacement curves of different wet friction materials. From Fig. 5(a), the fracture form of the samples is brittle. The tensile strength values (Fig. 5 (b)) of S1, S2, and S3 are 66.88, 77.96, and $109.77 \mathrm{MPa}$, respectively. S3 has improved tensile strength, which is due to its ability to adhere to the components. 

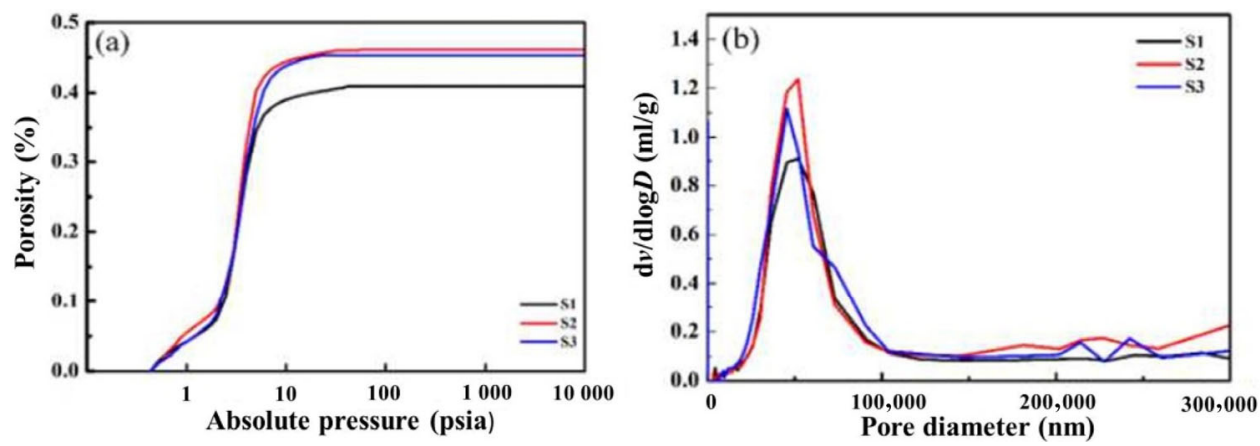

Fig. 4 (a) Porosity and (b) pore diameter of different samples.
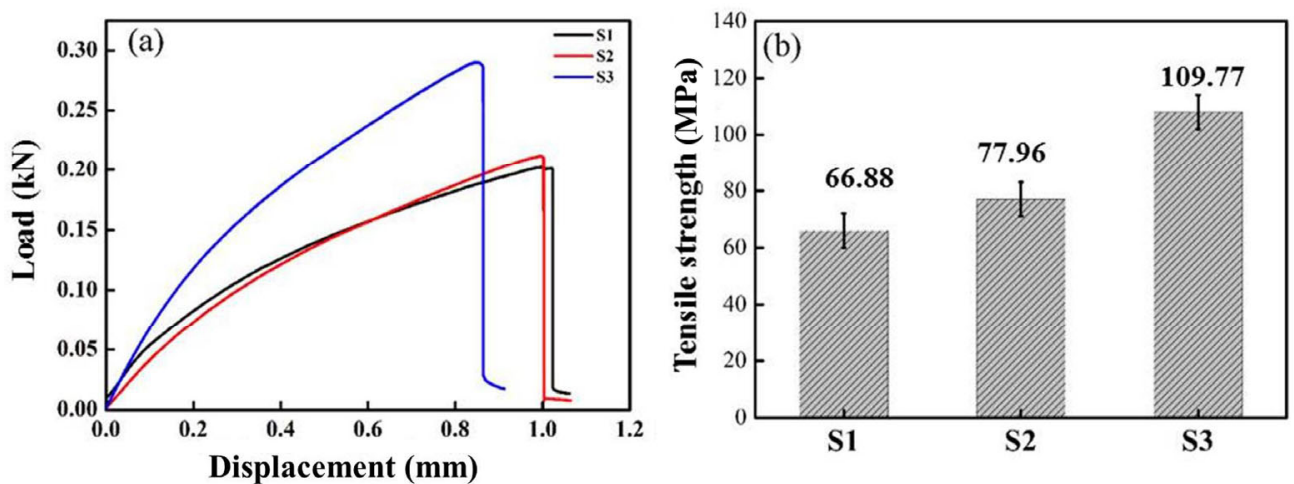

Fig. 5 (a) Load-displacement curves and (b) tensile strength of different samples.

\subsection{Thermal properties}

A large amount of friction heat can be generated during the braking process, and the instantaneous temperature could reach $300{ }^{\circ} \mathrm{C}$. This results in the decomposition of organic substances, thereby affecting the performance of wet friction materials. Therefore, it is important to study the heat resistance of these materials. To understand their thermal performance, TG-DTG curves were obtained, as shown in Fig. 6. Typical degradation temperatures and mass losses obtained from the TG and DTG curves are listed in Table 1. The three samples have similar thermal properties. Their $10 \%$ weight loss temperatures are approximately $415-430{ }^{\circ} \mathrm{C}$. The TG curves of the samples show two distinct regions of mass loss that are highlighted by two major peaks in the DTG curves. This implies that the friction material has at least two main stages of degradation. The maximum degradation temperature is $541-544{ }^{\circ} \mathrm{C}$ that is probably due to the decomposition of phenolic resin. The temperature loss in the second stage is approximately $570{ }^{\circ} \mathrm{C}$ because of the loss of fiber [4].

\subsection{Tribological performances}

\subsubsection{Friction torque curve}

The wet friction contact process includes three stages: flow dynamic lubrication, mixed lubrication stage, and boundary lubrication stage, which can be characterized by the friction torque curve [27, 28]. Figure 7 shows the friction torque curves of the different samples under the conditions of spindle inertia of $0.10 \mathrm{~kg} \cdot \mathrm{m}^{2}$, rotating speed of $1,000 \mathrm{rpm}$, and brake pressure of 0.5 MPa. Compared with S2 and S3, the friction torque curve of S1 changes more smoothly and there is no obvious "cock tail" in the torque curve. It can be concluded that the stability of the friction coefficient of S1 is the best. This indicates that it is not easy to produce chattering when the clutch is engaged. This might be due to the resilience of the nylon fibers, which can be cushioned during braking. However, the friction torque of S2 and S3 are significantly increased and the typical "cock tail" feature exhibited in the boundary lubrication stage. This may result in the vibration of the wet clutch in the braking process. 

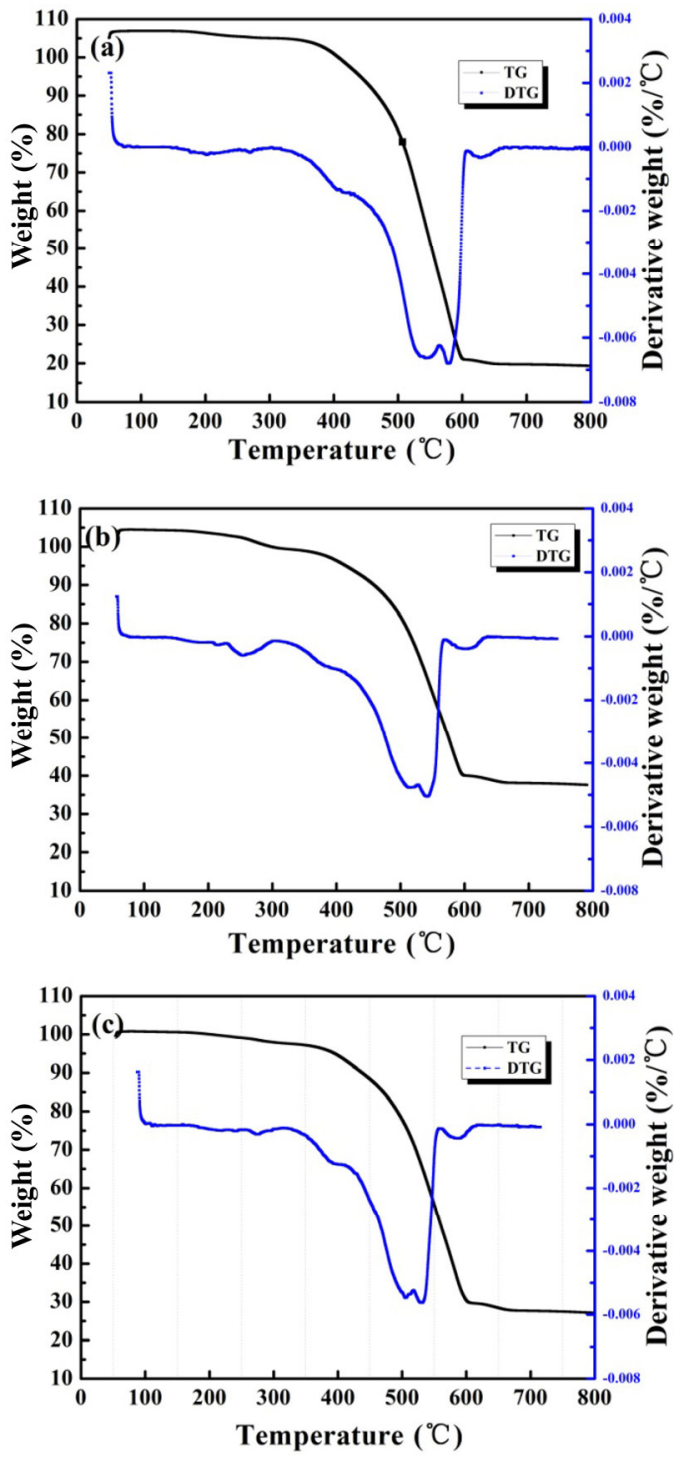

Fig. 6 TG-DTG curves of (a) S1, (b) S2, and (c) S3.

Table 1 Typical degradation temperatures.

\begin{tabular}{ccc}
\hline Sample & $T_{1}\left({ }^{\circ} \mathrm{C}\right)$ & $T_{2}\left({ }^{\circ} \mathrm{C}\right)$ \\
\hline S1 & 430.769 & 544.899 \\
S2 & 415.643 & 541.817 \\
S3 & 423.727 & 542.371
\end{tabular}

Note: $T_{1}$ is the temperature of $10 \%$ of mass loss, ${ }^{\circ} \mathrm{C} ; T_{2}$ is the temperature of maximum decomposition rate, ${ }^{\circ} \mathrm{C}$.

\subsubsection{Friction coefficient}

Figure 8 illustrates the dynamic friction coefficient and the static friction coefficient of the three samples. With the change of the conditions, the dynamic and static friction coefficients of traditional wet paper-based friction material can fluctuate under different speeds

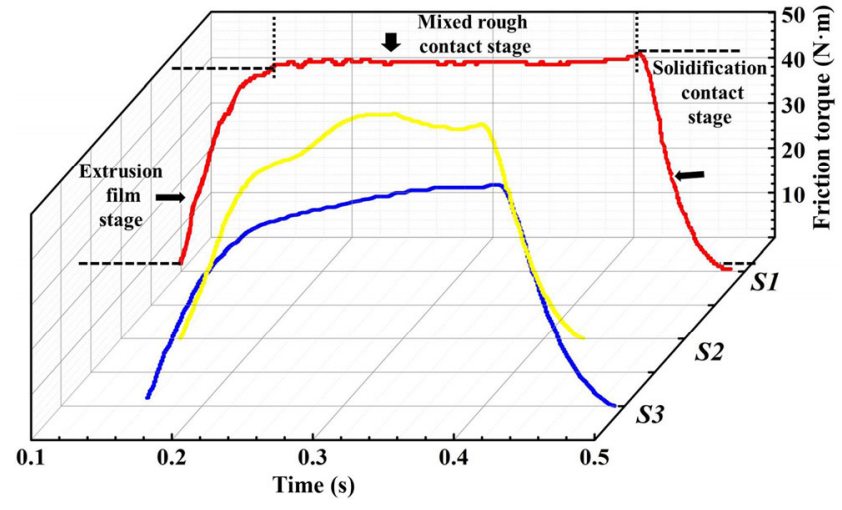

Fig. 7 Friction torque curves of different samples.

and pressures [2-5]. In this work, the rotation speed was unchanged, and the dynamic friction coefficient of the three samples decreased as the pressure increased from 0.5 to $2 \mathrm{MPa}$. For the three samples, when the pressure was constant, the dynamic friction coefficient increased when the rotational speed increased from 1,000 to $2,000 \mathrm{rpm}$. When the speed increases to $2,000 \mathrm{rpm}$, the oil on the surface of the friction material might undergo a transition from rich to lean. The thickness of the oil layer decreases, resulting in the increase of the friction coefficient. However, when the rotational speed changed from 2,000 to 3,000 rpm, the dynamic friction coefficient of the three samples decreases. This can be attributed to the increase of the rotational speed. As such, boundary lubrication might occur during braking. When operating in boundary lubrication or mixed lubrication, the hydrodynamic membrane might be a major factor that affects the friction coefficient of the samples [29-32]. It is evident from Fig. 4(a) that the porosity of the three samples is approximately $40 \%$, which can facilitate the entry of lubricant oil into the pores. During operation, the lubricant is adsorbed on the surface of the friction material due to the viscous action of the lubricating oil. When a sufficiently high speed is reached, the hydrodynamic lubrication creates a stable oil film between the friction material and the dual disk, ultimately resulting in the decrease of the friction coefficient of the samples. The static friction for each sample floating at \pm 0.005 may be determined using better fiber orientation and tangles. When the fibers are used to create NWF, the specific surface area increases and the fibers are dispersed uniformly. Fine fibers and fiber bundles on the surface of the samples (Figs. 3(a)-3(c)) 

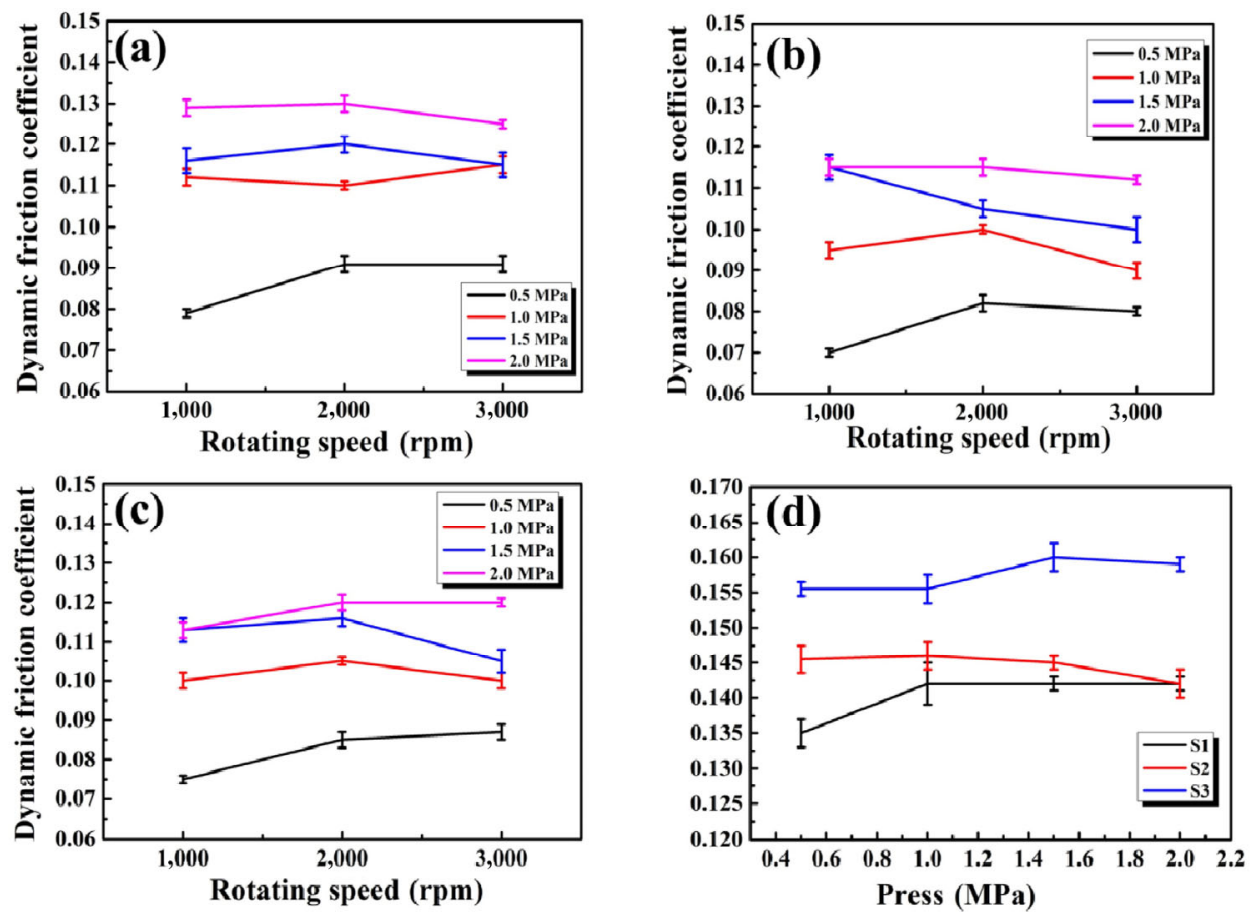

Fig. 8 Dynamic friction coefficient of (a) S1, (b) S2, and (c) S3; (d) static friction coefficient of three samples.

cause the bonding area between the fibers to increase. These undoubtedly guarantee the stability of the friction coefficient of the friction material.

\subsubsection{Wear rate}

The wear rate of the samples is shown in Fig. 9. The wear rates of S1, S2 and S3 are $0.81334 \times 10^{-14}, 1.70552 \times$ $10^{-14}$, and $4.01159 \times 10^{-14} \mathrm{~m}^{3} \cdot(\mathrm{N} \cdot \mathrm{m})^{-1}$, respectively. Among the three samples, it is concluded that $\mathrm{S} 1$ has the best wear resistance, followed by S2.

To investigate the reason for this phenomenon, SEM images of the worn surfaces of the samples were obtained, as shown in Figs. 10(a)-10(c). The reinforcing

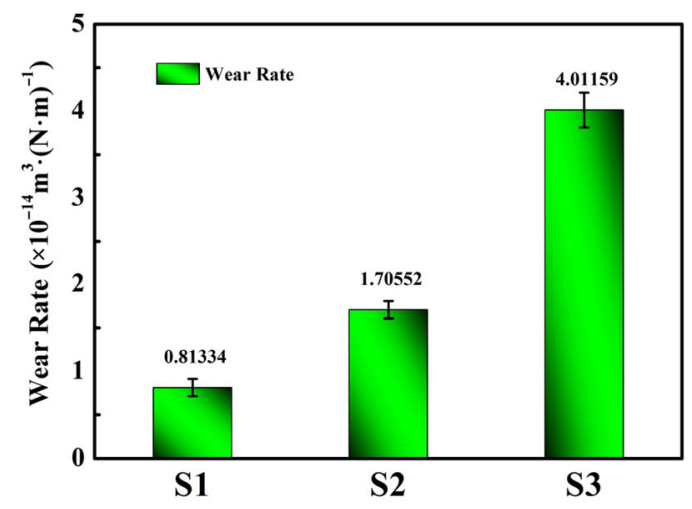

Fig. 9 Wear rate of different samples. ability of the fibers and the adhesive strength between the resin and the fibers are closely related to the wear resistance [33,34]. Due to the good binding ability between the resin binder and the other components for S1 and S2, they are tightly bonded. After rubbing, the surfaces of S1 and S2 become smooth, indicating that the surface damage of the two samples was not severe, which is consistent with the results for the wear rate [35]. Their worn surfaces appear to be attached with a smooth and dense friction film layer. However, the worn surface of S3 is uneven after wear, with many large holes and a small-area of friction film. The mixed fiber of S3 is a low melting point fiber that can be melted at $120{ }^{\circ} \mathrm{C}$ during hot pressing. However, for S3, low melting point fibers could soften and melt during the rubbing process, resulting in an increase in the thermal wear of S3. Moreover, given the poor wear resistance of the low-melting point fibers, they are easily rubbed off. The low-melting fibers not only lose their reinforcing effect for the samples, but also weaken the bond between the aramid fibers and the resin. This affects the structure of the entire RBFM, which results in poor adhesion between fibers and the resin. The poor combination of components causes S3 


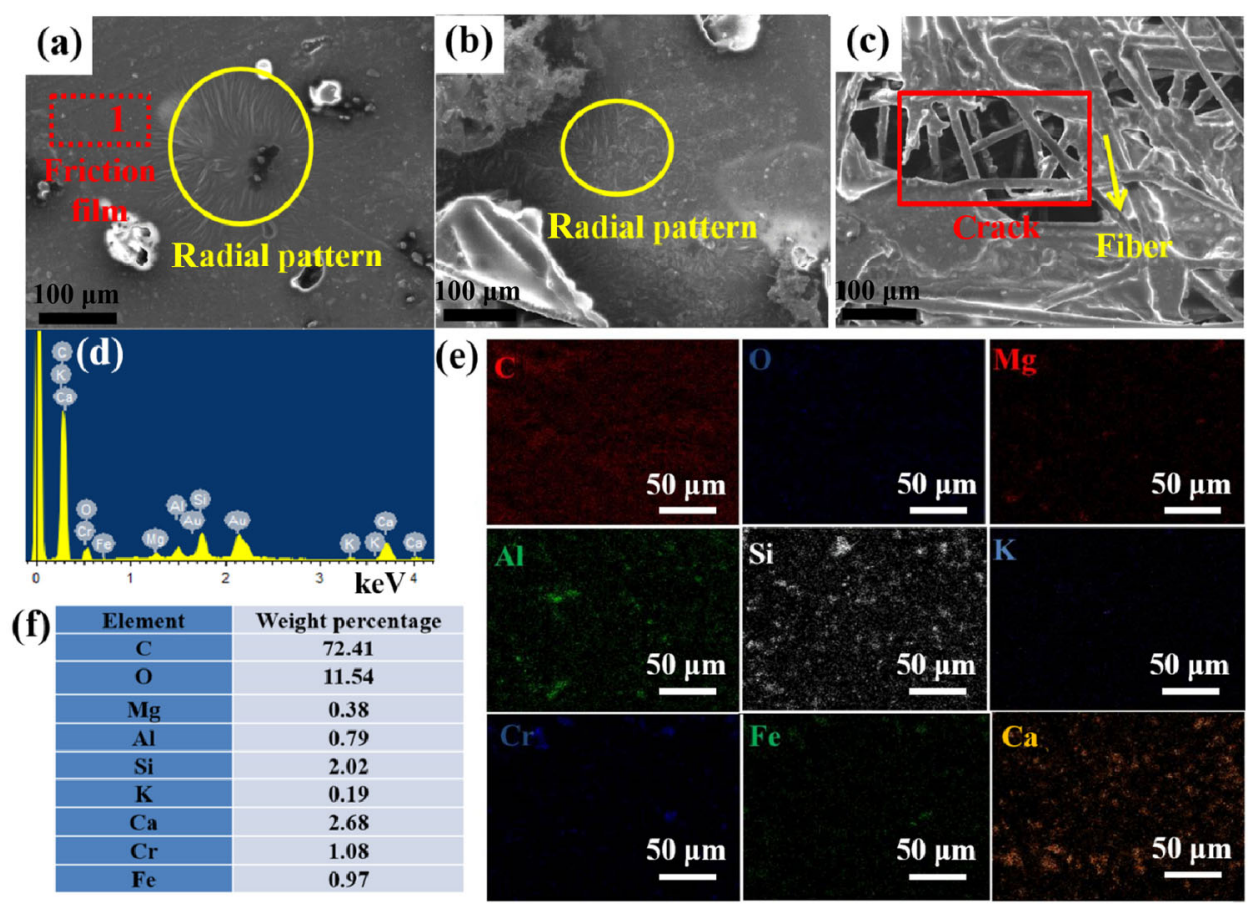

Fig. 10 SEM images of different samples: (a) S1, (b) S2, and (c) S3 after wear, (d) EDS spectroscopy, (e) elemental mapping, and (f) elemental weight percentage of worn surface for area 1 of S1.

to be easily damaged, which negatively affects the formation of the continuous friction film, resulting in poor wear resistance.

The reason for the difference in wear resistance of S1 and S3 could be explained with reference to Fig. 11. After braking, the surface state of the material might be as shown in Figs. 11(a) and 11(b). Combined with the microscopic morphology analysis after wear, it can be concluded that the degree of formation of the friction film is an important factor that affects wear resistance. When the fiber network is well-built (S1), it is easy to form a continuous friction film as shown in Fig. 11(c). Otherwise, a discontinuous friction film (Fig. 11(d)) is formed (S3).

The results for EDS elemental analysis of the worn surface for area 1 of $\mathrm{S} 1$ are shown in Figs. 10(d) and 10(f). It can be concluded that $\mathrm{C}, \mathrm{O}, \mathrm{Mg}, \mathrm{Al}, \mathrm{Si}, \mathrm{K}, \mathrm{Cr}$, $\mathrm{Fe}$, and $\mathrm{Ca}$ are the main elements of the friction film.

\subsection{Literature comparison and future perspectives}

Compared to traditional wet friction material (Fig. 12(a)), S1 and S2 have stable coefficients of friction and better (a)

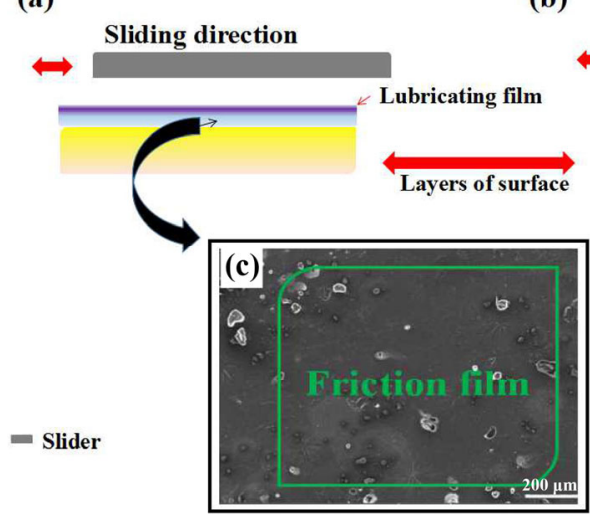

(b)

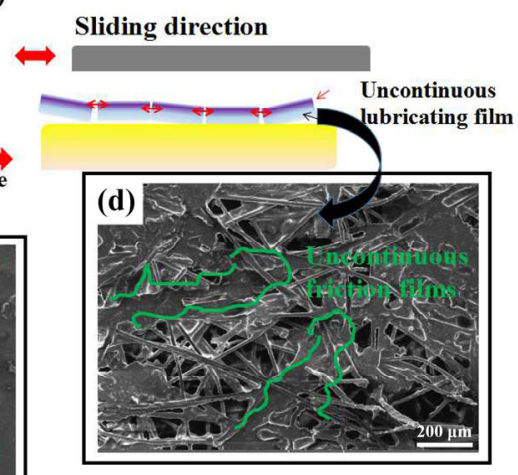

Fig. 11 Schematic diagram of possible behavior of different samples during actual working conditions under lubrication conditions: (a) S1 and (b) S3. Surface micrograph of friction film for (c) S1 and (d) S3. 
(a)

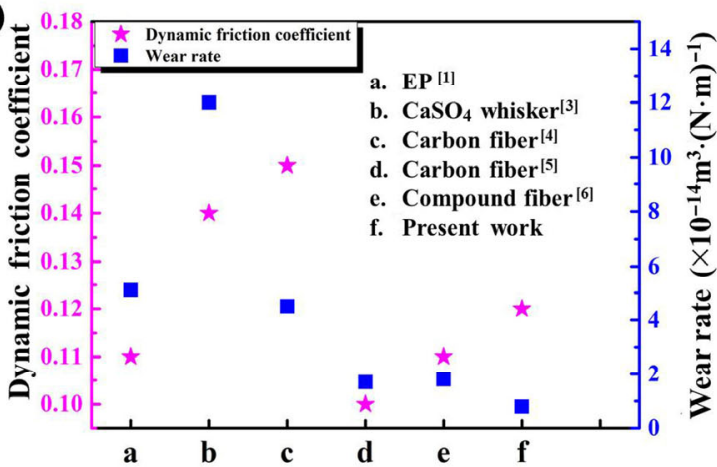

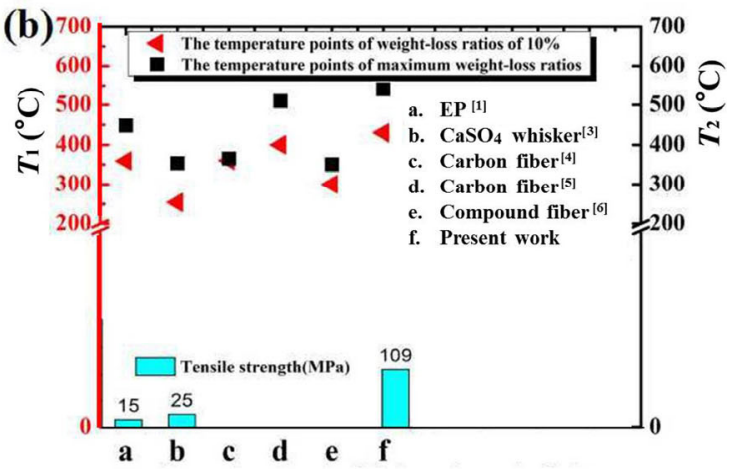

Fig. 12 (a) Tribological and (b) thermal properties and tensile strength of wet friction material have been studied.

wear resistance. Fine fibers were found filled with fiber skeletons built between long fibers. An NWF not only has a large specific surface area, but also the enhanced ability to combine the fiber, resin, and filler with excellent interfacial adhesion. In the network cavity, the physical interaction and hydrogen bonding forces among fibers are enhanced [36-38]. It acts as a "bridge", which increases the bond strength between the fibers, thereby increasing the wear resistance of the sample.

The tensile strength of S3 was greatly improved by approximately $600 \%$ compared to traditional friction materials and 360\% for S2, as displayed in Fig. 12(b). The significant enhancement of the tensile strength can be attributed to the increase in the length of the reinforcing fibers, and the structure of the reinforced fiber preform. Increasing the length of the reinforced fibers helps to improve the mechanical properties of the paper-based friction material [39, 40]. In addition, the intertwined entanglement of the NWF mitigates the pulling effect between fibers. This is different from conventional wet paper-based friction material, and contributes to the improvement of the mechanical properties of the new wet friction material.

The heat resistance of the new friction material increased by $100{ }^{\circ} \mathrm{C}$ compared to the conventional material, as shown in Fig. 12(b). The excellent heat resistance of the new wet friction material might be explained as follows: due to the large volume ratio of the "fiber skeleton" created by the reinforced fibers, a relatively large amount of inorganic fillers are used for the component of the new wet friction material. Therefore, the samples have outstanding heat resistant.

A novel approach is presented to fabricate wet friction materials, as an alternative to the traditional papermaking technology. It is worth noting that this new approach overcomes the existing limitations of paper-based friction materials associated with the traditional papermaking technology, such as the elimination of the traditional craft of the wet-type beating, conservation of water resources, as well as a reduction of energy consumption and pollution. This approach can be developed into a more environmentally-friendly wet friction material. Most importantly, textiles, including NWF and fiber felt can potentially be used as the reinforcement of FRRBFM for application to a variety of environments in the future.

\section{Conclusions}

A new and simple kind of wet friction material was explored. Three kinds of NWFs reinforced wet friction material were successfully prepared with excellent tribological, mechanical, and thermal properties. Under a pressure of $0.5 \mathrm{MPa}$, the dynamic friction coefficient of the new wet friction material can reach 0.12 , and its wear rate is as low as $0.81334 \times 10^{-14} \mathrm{~m}^{3} \cdot(\mathrm{N} \cdot \mathrm{m})^{-1}$. The tensile strength and $10 \%$ weight loss temperature of the material exceeded $66.88 \mathrm{MPa}$ and $400{ }^{\circ} \mathrm{C}$, respectively. Notably, the preparation strategy of the new material overcomes the existing limitations of paper-based friction material, which helps to conserve water and reduce energy consumption and pollution in the development of environmentally-friendly wet friction material. It is expected that the introduction of NWFs into friction material might complement various designs of FRRBFM. 


\section{Acknowledgements}

This work was supported by the National Key R\&D Program of China (Grant No. 2017YFB0308303), Shaanxi Province Technology Innovation Guide Special Project (Grant No. 2017CGZH-RGGJ-01), Shaanxi Provincial Key Research (Grant No. 2018ZDCXL-GY09-05), the Analytical \& Testing Center of Northwestern Polytechnical University, and the seed Foundation of Innovation and Creation for Graduate Students in Northwestern Polytechnical University (ZZ2019082).

Open Access This article is licensed under a Creative Commons Attribution 4.0 International License, which permits use, sharing, adaptation, distribution and reproduction in any medium or format, as long as you give appropriate credit to the original author(s) and the source, provide a link to the Creative Commons licence, and indicate if changes were made.

The images or other third party material in this article are included in the article's Creative Commons licence, unless indicated otherwise in a credit line to the material. If material is not included in the article's Creative Commons licence and your intended use is not permitted by statutory regulation or exceeds the permitted use, you will need to obtain permission directly from the copyright holder.

To view a copy of this licence, visithttp:// creativecommons.org/licenses/by/4.0/.

\section{References}

[1] Zhou L, Fu Y W, Yin T, Luo Z Y. Synergetic effect of epoxy resin and carboxylated nitrile rubber on tribological and mechanical properties of soft paper-based friction materials. Tribol Int 129: 314-322 (2019)

[2] Fei J, Luo D, Zhang C, Li H J, Cui Y L, Huang J F. Friction and wear behavior of sic particles deposited onto paperbased friction material via electrophoretic deposition. Tribol Int 119: 230-238 (2018)

[3] Zhang X, Li K Z, Li H J, Fu Y W. Investigation of the thermal property and tribological behavior of $\mathrm{CaSO}_{4}$ whiskermodified paper-based composite friction materials. Proc Inst Mech Eng Part J J Eng Tribol 231(12): 1583-1594 (2017)

[4] Fei J, Li H J, Fu Y W, Qi L H, Zhang Y L. Effect of phenolic resin content on performance of carbon fiber reinforced paperbased friction material. Wear 269(7-8): 534-540 (2010)
[5] Fei J, Wang H K, Huang J F, Zeng X R, Luo W. Effects of carbon fiber length on the tribological properties of paperbased friction materials. Tribol Int 72: 179-186 (2014)

[6] Zhang X, Li K Z, Li H J, Fu Y W, Fei J. Influence of compound mineral fiber on the properties of paper-based composite friction material. Proc Inst Mech Eng Part J J Eng Tribol 227(11): 1241-1252 (2013)

[7] Cai P, Li Z L, Wang T M, Wang Q H. Effect of aspect ratios of aramid fiber on mechanical and tribological behaviors of friction materials. Tribol Int 92: 109-116 (2015)

[8] Li H J, Fei J, Qi L H, Fu Y W, Li X T, Wang P Y. Effect of porosity percentage on the friction and wear performance of carbon fiber reinforced paper-based friction materials. $J$ Inorg Mater 22(6): 1159-1164 (2007)

[9] Madrid J F, Barsbay M, Abad L, Güven O. Grafting of N, $\mathrm{N}$-dimethylaminoethyl methacrylate from PE/PP nonwoven fabric via radiation-induced RAFT polymerization and quaternization of the grafts. Radiat Phys Chem 124: 145-154 (2016)

[10] Arora P, Zhang Z J. Battery separators. Chem Rev 104(10): 4419-4462 (2004)

[11] Martínez-Hergueta F, Ridruejo A, Gálvez F, González C, Llorca J L. Influence of fiber orientation on the ballistic performance of needlepunched nonwoven fabrics. Mech Mater 94: 106-116 (2016)

[12] Liu H J, Liu H L, Zhu C C, Wei P T, Tang J Y. Tribological behavior of coated spur gear pairs with tooth surface roughness. Friction 7(2): 117-128 (2019)

[13] Cho H R, Je Y, Chung K H. Assessment of wear characteristics of paper-based wet friction materials. Int J Precis Eng Manuf 19(5): 705-711 (2018)

[14] Gao H, Barber G C, Chu H. Friction characteristics of a paperbased friction material. Int J Automot Technol 3(4): 171-176 (2002)

[15] Miyazaki T, Matsumoto T, Yamamoto T. Effect of viscoelastic property on friction characteristics of paper-based friction materials for oil immersed clutches. J Tribol 120(2): 393-398 (1998)

[16] Enomoto Y, Yamamoto T. New materials in automotive tribology. Tribol Lett 5(1): 13-24 (1998)

[17] Fei J, Li H J, Qi L H, Fu Y W, Li X T. Carbon-fiber reinforced paper-based friction material: Study on friction stability as a function of operating variables. $J$ Tribol 130(4): 041605 (2008)

[18] Hu J T, Huang Y, Zeng X L, Li Q, Ren L L, Sun R, Xu J B, Wong C P. Polymer composite with enhanced thermal conductivity and mechanical strength through orientation manipulating of BN. Compos Sci Technol 160: 127-137 (2018) 
[19] Suresha B, Kumar K S, Seetharamu S, Kumaran P S. Friction and dry sliding wear behavior of carbon and glass fabric reinforced vinyl ester composites. Tribol Int 43(3): 602-609 (2010)

[20] Gopal P, Dharani L R, Blum F D. Fade and wear characteristics of a glass-fiber-reinforced phenolic friction material. Wear 174(1-2): 119-127 (1994)

[21] El-Tayeb N S, Gadelrab R M. Friction and wear properties of E-glass fiber reinforced epoxy composites under different sliding contact conditions. Wear 192(1-2): 112-117 (1996)

[22] Dong W P, Sullivan P J, Stout K J. Comprehensive study of parameters for characterising three-dimensional surface topography: III: Parameters for characterising amplitude and some functional properties. Wear 178(1-2): 29-43 (1994)

[23] Zhou P, Zhao F L. 3D evaluation method of cutting surface topography of carbon/carbon $(\mathrm{C} / \mathrm{C})$ composite. High Technol Lett 16(41): 366-372 (2010)

[24] Zhou P, Zhao F L. 3D evaluation method of cutting surface topography of carbon/phenolic $(\mathrm{C} / \mathrm{Ph})$ composite. $J$ Wuhan Univ Technol Mater Sci Ed 26(3): 459-463 (2011)

[25] Zhang X, Li K Z, Li H J, Fu Y W, Fei J. Tribological and mechanical properties of glass fiber reinforced paper-based composite friction material. Tribol Int 69: 156-167 (2014)

[26] Matsumoto T. The influence of paper-based friction material porosity on the performance of a wet clutch. SAE Technical Papers, 941032 (1994)

[27] Berger E J, Sadeghi F, Krousgrill C M. Torque transmission characteristics of automatic transmission wet clutches: Experimental results and numerical comparison. Tribol Trans 40(4): 539-548 (1997)

[28] Natsumeda S, Miyoshi T. Numerical simulation of engagement of paper based wet clutch facing. J Tribol 116(2): 232-237 (1994)

[29] Liang H, Guo D, Luo J B. Film forming behavior in thin film lubrication at high speeds. Friction 6(2): 156-163 (2018)

[30] Jacko M G, Tsang P H S, Rhee S K. Wear debris compaction and friction film formation of polymer composites. Wear 133(1): 23-28 (1989)

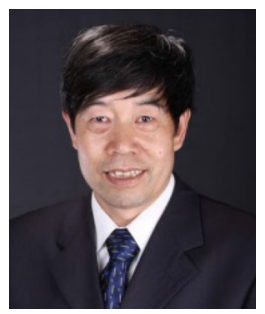

YeWei FU. He received his Ph.D. in materials science in 2005 from Northwestern Polytechnical University, Xi'an, China. He has overcome
[31] Guo L, Wong P, Guo F. Identifying the optimal interfacial parameter correlated with hydrodynamic lubrication. Friction 4(4): 347-358 (2016)

[32] Wang A Y, Yan S, Lin B, Zhang X F, Zhou X X. Aqueous lubrication and surface microstructures of engineering polymer materials (PEEK and PI) when sliding against $\mathrm{Si}_{3} \mathrm{~N}_{4}$. Friction 5(4): 414-428 (2017)

[33] Liu Y C, Wang L N, Liu D X, Ma Y H, Tian Y, Tong J, Senthamaraikannand P, Saravanakumar S. Evaluation of wear resistance of corn stalk fiber reinforced brake friction materials prepared by wet granulation. Wear 432-433: 102918 (2019)

[34] Hwang H J, Jung S L, Cho K H, Kim Y J, Jang H. Tribological performance of brake friction materials containing carbon nanotubes. Wear 268(3-4): 519-525 (2010)

[35] Ji Z J, Luo W Y, Zhou K K, Hou S E, Zhang Q F, Li J Y, Jin $H$ Y. Effects of the shapes and dimensions of mullite whisker on the friction and wear behaviors of resin-based friction materials. Wear 406-407: 118-125 (2018)

[36] Banavath H N, Bhardwaj N K, Ray A K. A comparative study of the effect of refining on charge of various pulps. Bioresour Technol 102(6): 4544-4551 (2011)

[37] Korehei R, Jahangiri P, Nikbakht A, Martinez M, Olson J. Effects of drying strategies and microfibrillated cellulose fiber content on the properties of foam-formed paper. $J$ Wood Chem Technol 36(4): 235-249 (2016)

[38] Lee T W, Lee S, Park S M, Lee D. Mechanical, thermomechanical, and local anisotropy analyses of long basalt fiber reinforced polyamide 6 composites. Compos Struct 222: 110917 (2019)

[39] Gharehkhani S, Sadeghinezhad E, Kazi S N, Yarmand H, Badarudin A, Safaei M R, Zubir M N M. Basic effects of pulp refining on fiber properties-A review. Carbohyd Polym 115: 785-803 (2015)

[40] Lohr C, Beck B, Henning F, Weidenmann K A, Elsner P. Mechanical properties of foamed long glass fiber reinforced polyphenylene sulfide integral sandwich structures manufactured by direct thermoplastic foam injection molding. Compos Struct 220: 371-385 (2019)

many key technologies in the research of advanced preparation technology for high-performance paperbased friction materials. 


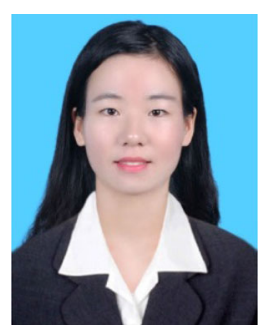

Le ZHOU. She received her bachelor

student in the School of Materials Science and degree in Inorganic Non-metallic Materials Engineering in 2017 from Liaoning University, Shenyang, China. After then, she is a M.S.

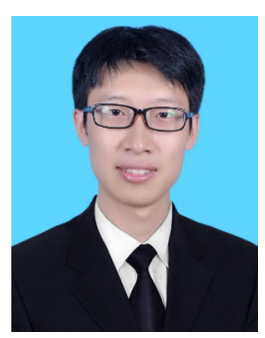

Tao YIN. He received his bachelor degree in compound materials and engineering in 2017 from Northwestern Polytechnical University,

Xi'an, China. After then, he is a M.S. student in the School of Materials Science and Engineering of Northwestern Polytechnical University, Xi'an, China. His research interest is resin-based friction materials. 